\title{
Physiological and photosynthetic response of quinoa to drought stress
}

\author{
Rachid Fghire $^{1 *}$, Fatima Anaya ${ }^{1}$, Oudou Issa Ali ${ }^{1}$, Ouafae Benlhabib ${ }^{2}$, Ragab Ragab ${ }^{3}$, and Said Wahbi
}

Water shortage is a critical problem touching plant growth and yield in semi-arid areas, for instance the Mediterranean region. For this reason was studied the physiological basis of drought tolerance of a new, drought tolerant crop quinoa (Chenopodium quinoa Willd.) tested in Morocco in two successive seasons, subject to four irrigation treatments (100, 50 , and $33 \%$ ETc, and rainfed). The chlorophyll a fluorescence transients were analyzed by the JIP-test to translate stressinduced damage in these transients to changes in biophysical parameter's allowing quantification of the energy flow through the photosynthetic apparatus. Drought stress induced a significant decrease in the maximum quantum yield of primary photochemistry $\left(\phi_{\mathrm{P} 0}=\mathrm{F}_{\mathrm{v}} / \mathrm{F}_{\mathrm{m}}\right)$, and the quantum yield of electron transport $\left(\phi_{\mathrm{E} 0}\right)$. The amount of active Photosystem II (PSII) reaction centers (RC) per excited cross section (RC/CS) also decreased when exposed to the highest drought stress. The effective antenna size of active RCs (ABS/RC) increased and the effective dissipation per active reaction centers (DIo/RC) increased by increasing drought stress during the growth season in comparison to the control. However the performance index (PI), was a very sensitive indicator of the physiological status of plants. Leaf area index, leaf water potential and stomatal conductance decreased as the drought increased. These results indicate that, in quinoa leaf, JIP-test can be used as a sensitive method for measuring drought stress effects.

Key words: Drought, fluorescence, JIP-test, leaf water potential, quinoa, stomatal conductance.

\section{INTRODUCTION}

Water shortage is a serious problem affecting plant growth and yield in the Mediterranean region (Souza et al., 2004). Water deficit affects cell turgidity and stomatal aperture of leaves resulting in decreases in both transpiration rates and $\mathrm{CO}_{2}$ assimilation, which inhibits leaf metabolism (Souza et al., 2004; Dos Santos et al., 2006; Waseem et al., 2011). Under reduced rate of $\mathrm{CO}_{2}$ assimilation, the equilibrium between photochemical activity at photosystem II (PSII) and electron requirement for photosynthesis is affected, generating an over excitation on photosynthetic system and photoinhibitory damages of PSII reaction centers, RCs (van Heerden et al., 2003; Albert et al., 2011).

The functional state of photosynthetic apparatus is a useful physiological indicator to study the sensibility of plants to environmental abiotic stress, such as salinity (Liu and Shi, 2010; Mehta et al., 2010), oil contamination (Gao and Tam, 2011), nutritional deficiency (Han et al., 2009; Lin et al., 2009; Liu and Shi, 2010), high light

${ }^{1}$ Université Cadi Ayyad, Faculté des Sciences Semlalia, BP2390, Marrakech, Maroc. "Corresponding author (r.fghire@gmail.com).

${ }^{2}$ Institut Agronomique et Vétérinaire Hassan II, Département Production, Protection et Biotechnologies Végétales, Rabat, Maroc. ${ }^{3}$ Centre for Ecology and Hydrology (CEH), Wallingford OX10 8BB, UK.

Received: 31 May 2014.

Accepted: 17 January 2015.

doi:10.4067/S0718-58392015000200006 exposure (Cascio et al., 2010) and drought (Shao et al., 2010; Strasser et al., 2010; Tsonev et al., 2014). Under drought conditions, in vivo chlorophyll a fluorescence analyses have provided extensive information about structure and function of the photosynthetic machinery (Papageorgiou and Govindjee, 2004). The changes in primary photochemistry of Photosystem II (PSII), caused by abiotic stress, have been investigated widely basing on the chlorophyll fluorescence. An additional approach, the JIP-test, has been developed, which analyses $\mathrm{Chl}$ a fluorescence transient using the continuous excitation fluorometer (Strasser et al., 2000). This technique has been used to analyze the rapid $\mathrm{Chl}$ a fluorescence transients giving insight into primary photochemistry.

The fluorescence yield of PSII is calculated by the state of the reaction centers (RCs) (Christen et al., 2007), i.e. open or closed. In the dark, the quinone $\left(\mathrm{Q}_{\mathrm{A}}\right)$, primary electron acceptor of PSII is presumed to be in oxidized state suggesting all RCs are open and the fluorescence intensity at this point of time (onset of illumination) is minimal $\left(\mathrm{F}_{0}\right)$. The fast fluorescence rise due to the strong actinic light results in maximum fluorescence $\left(\mathrm{F}_{\mathrm{m}}\right)$ owing to closure of all reaction centers (where $\mathrm{Q}_{\mathrm{A}}$ is in the reduced state). Chronological events reflected in the fluorescence kinetic rise progress at different rates and results in the polyphasic fluorescence rise, designated by the letters $\mathrm{O}$ (initial fluorescence), J (2 ms), I (30 ms) and $\mathrm{P}(500 \mathrm{~ms}$ ) (Strasser and Strasser 1995; Strasser et al., 2004). The OJ phase reflects partial $\mathrm{Q}_{\mathrm{A}}$ reduction and 
corresponds to a single turnover photochemical event. The JI phase mainly reflects the reduction of the intersystem electron carriers, such as the secondary electron acceptor quinone (Qb), plastoquinone (PQ), cytochrome (Cyt) and plastocyanin (PC). The IP phase reflects the reduction of PSI electron acceptors such as ferredoxin (Fa), NADP and other intermediates (Yusuf et al., 2010).

The high sensitivity of plant responses to the alterations, induced on the photosynthetic system, especially PSII (Mehta et al., 2010), render the Chl a fluorescence the most used method in species and genotypes monitoring and screening for stress tolerance.

The use of drought tolerant cultivars can increase productivity in water-deficient environments. Crop tolerance to low water availability requires the ability to maintain vital functions of the cellular metabolism under conditions of water deficit, as well as rapid recovery of water status and plant function after stress (Waseem et al., 2011). This requires synthesis of compounds with osmotic activity, increased rigidity of cell walls, small cells, adjustment of volumetric elastic modulus (e) and photosynthetic activity (Chaves et al., 2003; Redillas et al., 2011; Fghire et al., 2013). The responses to drought are species specific and often genotype specific.

There is no much literature on the using of florescence in quinoa plant, Sanchez et al. (2003) indicate that the maximum quantum yield of primary photochemistry $\left(\mathrm{F}_{\mathrm{v}} / \mathrm{F}_{\mathrm{m}}\right)$ and quenching analysis showed that dehydrated plants are less protected from photoinhibition. However Winkel et al. (2002) indicate that $F_{v} / F_{m}$ was not sensitive to water stress. Shabala et al. (2012) indicate that quinoa growing under salt stress present a higher $\mathrm{F}_{\mathrm{v}} / \mathrm{F}_{\mathrm{m}}$ values compared with control plants after UV-B exposure.

The aim of this study was to investigate whether the JIP-test parameters can be used as a reliable indicator of drought stress in quinoa leaves.

\section{MATERIALS AND METHODS}

\section{Plant material and experiment design}

The study was carried out on quinoa (Chenopodium quinoa Willd.) 'Puno', provided by the project "Sustainable water use securing food production in dry areas of the Mediterranean region (SWUP-MED)". Seeds were sown on a sandy loam soil of farmer's field at "Tnin Bouchan" located at $70 \mathrm{~km} \mathrm{NW}$ of Marrakech $\left(32^{\circ} 14.6267^{\prime} \mathrm{N}\right.$, $8^{\circ} 19.8181$ ' W, $280 \mathrm{~m}$ a.s.1.), Morocco. Field trials were conducted from February through June at two successive seasons (2011 and 2012).

The main physical and chemical properties were determined in situ and in laboratory at the beginning of the trial for 0-60 cm depth (Table 1).

Four irrigation treatments were tested, rainfed and three irrigation treatments $(100 \%, 50 \%$, and $33 \%$ of crop evapotranspiration [ETc]). The experimental design was randomized blocks with four plot replicates of $6 \times 5 \mathrm{~m}$ per
Table 1. The main soil physical and chemical properties for $0-60 \mathrm{~cm}$ soil depth.

\begin{tabular}{lc}
\hline Parameters & Profile $0-60 \mathrm{~cm}$ depth \\
Texture & $\begin{array}{c}\text { 62\% sand, 36\% silt, 12\% clay } \\
\text { sandy loam soil }\end{array}$ \\
\hline $\mathrm{pH}$ & 7.41 \\
Electric conductivity, $\mu \mathrm{s} \mathrm{cm}^{-1}$ & 275 \\
Total N, $\mathrm{mg} \mathrm{g}^{-1}$ & 2.50 \\
Ammoniac N, $\mathrm{mg} \mathrm{g}^{-1}$ & 1.66 \\
Total organic C, \% & 0.54 \\
Organic matter, \% & 0.93 \\
Chloride, $\mathrm{mg} \mathrm{g}^{-1}$ & 0.41 \\
Total P, $\mathrm{mg} \mathrm{g}^{-1}$ & 0.04 \\
Field capacity, $\mathrm{m}^{3} \mathrm{~m}^{-3}$ & 0.32 \\
Permanent wilting point, $\mathrm{m}^{3} \mathrm{~m}^{-3}$ & 0.04 \\
Porosity, $\mathrm{m}^{3} \mathrm{~m}^{-3}$ & 0.45 \\
\hline
\end{tabular}

plot. Quinoa seeds were sown directly on a sandy loam soil (60\% sand, $30 \%$ silt, and $10 \%$ clay) at $0.2 \mathrm{~m}$ spacing between pits of the same row and $0.8 \mathrm{~m}$ between rows. A buffer area of $1 \mathrm{~m}$ preserved between experimental units to avoid border and interaction effects.

Meteorological data (Figure 1) (minimum and maximum temperatures, minimum and maximum relative humidity, wind speed, solar radiation) were permanently measured by weather stations (iMETOS ag, Pessl Instruments, Weiz, Austria) installed in the field and automatically sent to internet climate data base.
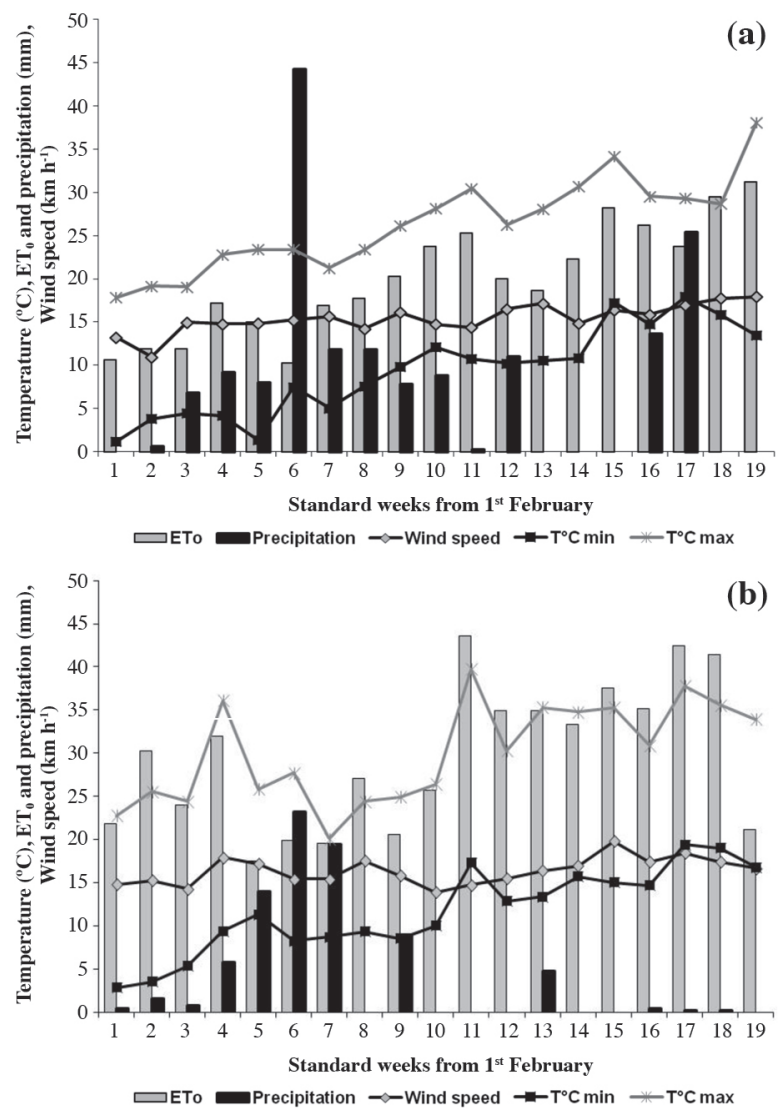

Figure 1. Site weather data during the growing seasons 2011(a) and 2012 (b). 
Daily irrigation was based on reference evapo transpiration $\left(\mathrm{ET}_{0}\right)$, calculated with the FAO-PenmanMonteith equation (Allen et al., 1998) from the meteorological data. The net irrigation requirement is derived from the field water balance equation (Andreas and Karen, 2002), and was efficiently applied by drip irrigation. Drip emitters were spaced $0.10 \mathrm{~m}$ along the lateral with a discharge of $1 \mathrm{~L} \mathrm{~h}^{-1}$ under an operation pressure of $1.5 \mathrm{~kg} \mathrm{~cm}^{-2}$. The rate of water flow in all drip laterals was equal and constant under all the treatments.

\section{Physiological and photosynthetic measurements}

Stomatal conductance $\left(\mathrm{g}_{\mathrm{s}}\right)$ was measured at midday during the whole growing season with a portable porometer (Leaf Porometer, Decagon Devices, Pullman, Washington, USA). The device was calibrated before use on every occasion using the supplied calibration plate. The terminal part of the main leaf lobe was placed into the cup on the head unit which was positioned normal to the sun. Measurements were conducted during cloudless periods on exposed leaves around noon.

Midday leaf water potential $(\Psi)$ was measured using a Scholander pressure chamber (SKPD 1400, Skye Instruments, Powys, UK). A branch with four newly expanded leaves per plant (four plants per treatment) was detached, enclosed in a plastic bag, immediately severed at the petiole, and scaled into the humidified chamber for determination of balancing pressure.

LAI was estimated with a $0.8 \mathrm{~m}$ long ceptometer (Decagon Devices) between 11:30 and 14:00 h on clear days. Four measurements were taken in each replicate. The measurements were taken at soil surface level placing the sensor below the canopy and moving it parallel to rows at regular intervals.

Developmental stages (recorded when three out of five sampled plants within each plot reached the stage) were determined as: emergence, visible flower bud (Bertero et al., 1999), first anthesis (at least one flower opened), physiological maturity (visually determined from examination of seeds on the medium third of the inflorescence), and senescence when plant start losing leaves. These stages defined four developmental phases: emergence, vegetative, flowering, grain filling, and senescence.

OJIP fluorescence transients recorded in control (100\%ETc) and drought stressed plants at the successive development stages (emergence, vegetative, flowering, grain filing, and senescence stages) were analyzed in two successive years under field conditions.

The initial stage of photosynthetic activity of a RC complex is regulated by three functional steps namely absorption of light energy (ABS), trapping of excitation energy (TR), and conversion of excitation energy to electron transport (ET). Therefore, JIP-test parameters give a useful indication on how drought stress affects the distribution of energy in PSII.
Chlorophyll fluorescence was measured at each growth stage, using a plant efficiency analyzer (Handy PEA, Hansatech Instruments, King's Lynn, UK). Leaves were adapted to darkness for $20 \mathrm{~min}$, and then exposed to a saturating red light pulse $(650 \mathrm{~nm}, 3000 \mu \mathrm{mol}$ photons $\mathrm{m}^{-2} \mathrm{~s}^{-1}$ ) flashed by an array of three light-emitting diodes on a homogeneous irradiation area of $12.5 \mathrm{~mm}^{2}$. The measured data were used for the calculation according to the JIP-test equations (Strasser et al., 2000; 2004; 2010). The following fluorescence intensity values from the original measurements were used: minimal intensity at $50 \mu \mathrm{s}$, when all PSII RC are open (the O step); intensity at $300 \mu \mathrm{s}$ used for calculation of the initial slope (Mo), defined as the net ratio of RC closure: the intensity at 2 $\mathrm{ms}$ (the J step), the intensity at $30 \mathrm{~ms}$ (the I step), and the maximal intensity when all PSII RCs are closed (P step = FM). The biophysical parameters derived from the OJIP transients were calculated, and the following parameters, which refer to time of maximal intensity, were used: (i) Flux ratio of PSII; $\left(\phi_{\mathrm{P} 0}=\mathrm{f}_{\mathrm{v}} / \mathrm{f}_{\mathrm{m}}\right)$, the maximum quantum yield of primary photochemistry; and $\phi_{\mathrm{E} 0}$ the quantum yield of electron transport; (ii) flux ratios of PSI: $\phi_{\mathrm{R} 0}$, the quantum yield of electron transport from $\mathrm{Q}_{\mathrm{A}}^{-}$to the PSI end electron acceptors (iii) specific energy fluxes per RC; absorption (ABS/RC); electron transport $\left(\mathrm{ET}_{0} /\right.$ $\mathrm{RC})$; trapping $\left(\mathrm{TR}_{0} / \mathrm{RC}\right)$; and dissipation $\left(\mathrm{DI}_{0} / \mathrm{RC}\right)$; (iv) phenomenological energy fluxes per excited cross section (CSm, subscript $m$ refer to time $\mathrm{F}_{\mathrm{m}}$ ): absorption (ABS/ $\left.\mathrm{CSm}=\mathrm{F}_{\mathrm{m}}\right)$ electron transport $\left(\mathrm{ET}_{0} / \mathrm{CSm}\right)$; trapping $\left(\mathrm{TR}_{0} /\right.$ $\mathrm{CSm})$; dissipation $\left(\mathrm{DI}_{0} / \mathrm{CSm}\right)$; and density of $\mathrm{RCs}(\mathrm{RC} /$ $\mathrm{CSm}$ ); (v) Performance index (PI) that provides useful quantitative information about the state of plants and their vitality (Kalaji et al., 2011a; 2011b) and therefore can be used for the analysis of plant stress response (Oukarroum et al., 2007).

\section{Statistical analysis}

The experimental layout was a randomized blocks design. Data were statistically analyzed by repeated ANOVA (split split plot) using CoStat software.

\section{RESULTS}

Stomatal conductance $\left(g_{s}\right)$ during the experimentation showed higher values at the beginning of the experimentation (Figure 2), with values ranging from 322 to $420 \mathrm{mmol}\left(\mathrm{H}_{2} \mathrm{O}\right) \mathrm{m}^{-2} \mathrm{~s}^{-1}$ for rainfed treatment and $100 \%$ ETc respectively. Thereafter, gs gradually decreased until the end of the experiment, these reductions ranged between $22 \%$ and $24 \%$ for rainfed plant, and between $14 \%$ and $22 \%$ for $33 \%$ ETc. In the second season a reduction of $61 \%$ was recorded under rain feed treatment after 3 wk of treatment applying, at the end of experimentation the reductions were greater than $70 \%$. However, in semiirrigated treatment $(50 \%$ ETc) maximal stomatal closure was less than $48 \%$. Stomatal conductance was significantly 


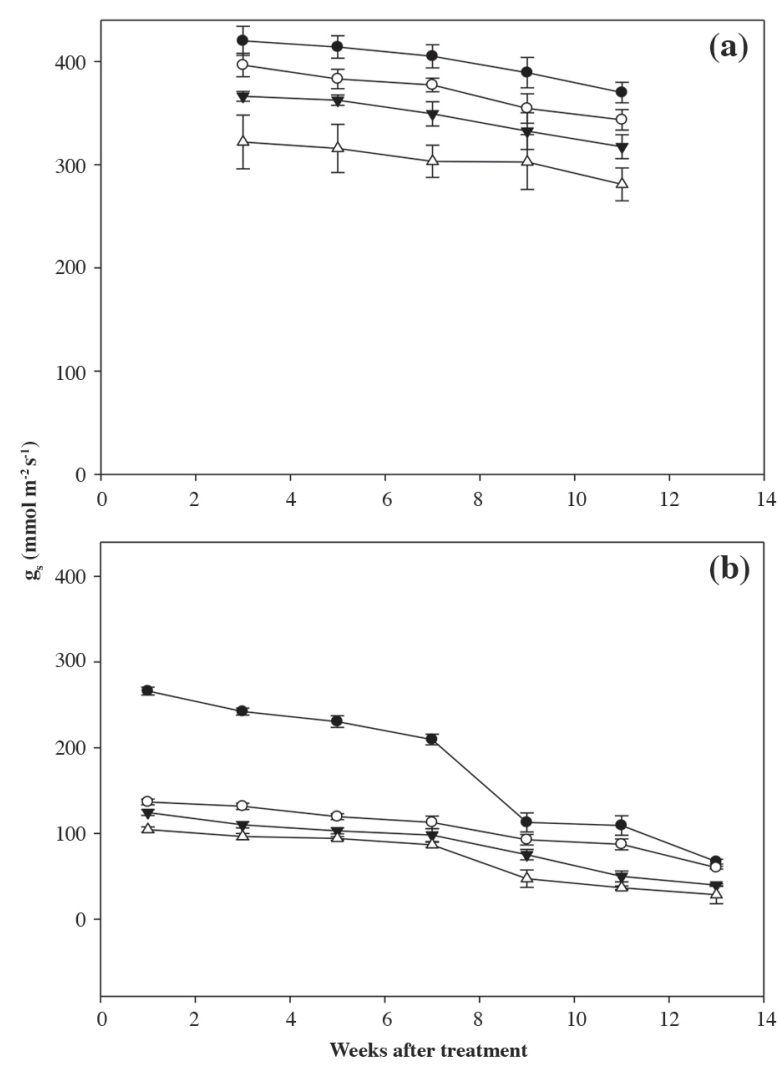

Irrigation treatments: $100 \% \mathrm{ETc}(\bullet), 50 \% \mathrm{ETc}(\circ), 33 \% \mathrm{ETc}(\boldsymbol{\Delta})$, and rain fed $(\Delta)$. Values are means $( \pm$ SE) of four replicates.

Figure 2. Stomatal conductance $\left(\mathrm{g}_{\mathrm{s}}\right)$ in 2011 (a) and 2012 (b) under four level of irrigation treatments: well watered $(100 \% \mathrm{ETc})$, $50 \% \mathrm{ETc}, 33 \% \mathrm{ETc}$, and rainfed.

affected by growth stage and by the interaction effect of irrigation treatment and growth stage in both seasons (Table 2). The large difference in climate condition in both seasons (Figure 1), had a significant effect on the $\mathrm{g}_{\mathrm{s}}$ resulted to an important inter-annual difference in $\mathrm{g}_{\mathrm{s}}$.
The effect of increasing drought on $\Psi_{\mathrm{L}}$ is seen in Figure 3. Throughout the experiment, $\Psi_{\mathrm{L}}$ values for $100 \% \mathrm{ETc}$ plants were maintained between -0.4 and $-0.9 \mathrm{MPa}$. Leaf water potential decreased slightly during the first $8 \mathrm{wk}$ after the beginning of the treatments, and then $\Psi_{\mathrm{L}}$ values decreased substantially for all treatments, from -1.0 to -3 MPa for rainfed treatment. Irrigation treatments, growth stages, and their interaction had significant influence on

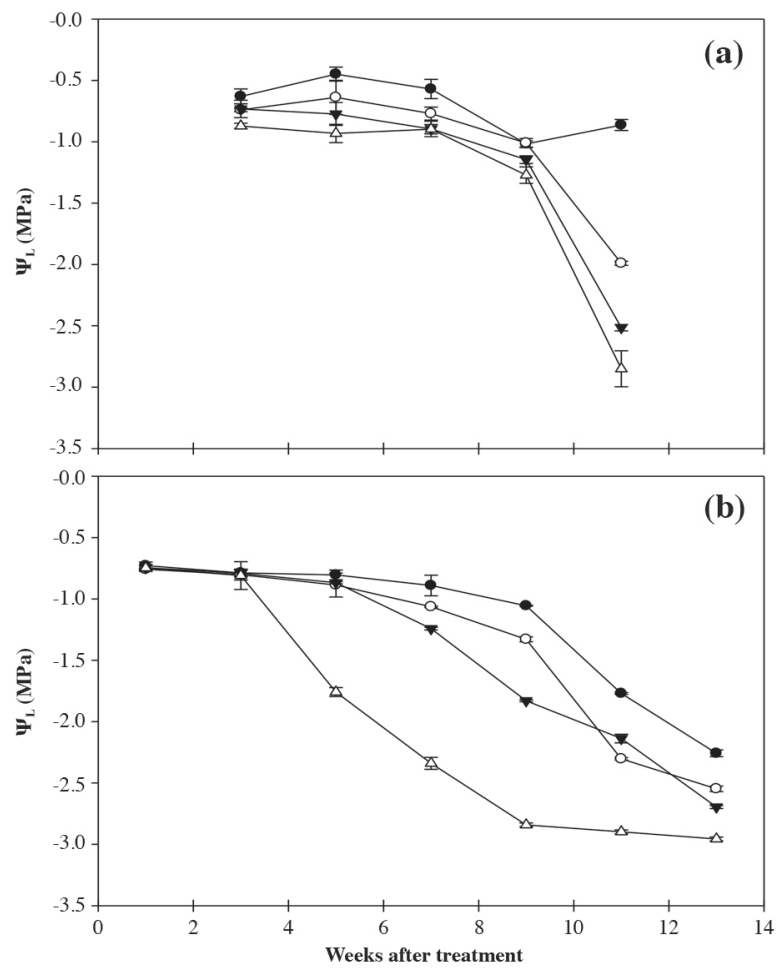

Irrigation treatments: $100 \% \mathrm{ETc}(\bullet), 50 \% \mathrm{ETc}(\mathrm{\circ}), 33 \% \mathrm{ETc}(\boldsymbol{\Delta})$, and rain fed $(\Delta)$. Values are means $( \pm$ SE) of four replicates.

Figure 3. Daily minimum leaf water potential $\left(\Psi_{\mathrm{L}}\right)$ in 2011 (a) and 2012 (b) under four level of irrigation treatments: well watered $(100 \% \mathrm{ETc}), 50 \% \mathrm{ETc}, 33 \% \mathrm{ETc}$, and rain fed.

Table 2. Statistical significance (P) of irrigation treatment (IT) growth stage (GS) an IT $\times$ GS interaction on JIP-test data.

Parameters

Leaf water potential $\left(\Psi_{\mathrm{L}}\right)$

Stomatal conductance $\left(\mathrm{g}_{\mathrm{s}}\right)$

Leaf area index (LAI)

Performance index (PI)

Reaction center per cross section (RC/CSm)

Absorption of energy per cross section (ABS/CSm)

Trapping energy per cross section $\left(\mathrm{TR}_{0} / \mathrm{CSm}\right)$

Electron transport per cross section $\left(\mathrm{ET}_{0} / \mathrm{CSm}\right)$

Dissipation of energy per cross section $\left(\mathrm{DI}_{0} / \mathrm{CSm}\right)$

Quantum yield of electron transport from $\mathrm{Q}_{\mathrm{A}}^{-}$to the photosystem I

(PSI) end electron acceptor $\left(\phi_{\mathrm{R} 0}\right)$

Maximum quantum yield of primary photochemistry $\left(\phi_{\mathrm{P} 0}\right)$

Quantum yield of electron transport from QA to plastoquinone $\left(\phi_{\mathrm{E} 0}\right)$

Absorption of energy per relational center (ABS/RC)

Trapping of energy per relational center $\left(\mathrm{TR}_{0} / \mathrm{RC}\right)$

Electron transport per relational center $\left(\mathrm{ET}_{0} / \mathrm{RC}\right)$

Dissipation of energy per relational center $\left(\mathrm{DI}_{0} / \mathrm{RC}\right)$

\begin{tabular}{|c|c|c|c|c|c|}
\hline \multicolumn{3}{|c|}{2011} & \multicolumn{3}{|c|}{2012} \\
\hline $\begin{array}{c}\text { Irrigation } \\
\text { treatment (IT) }\end{array}$ & $\begin{array}{c}\text { Growth } \\
\text { stage (GS) }\end{array}$ & $\mathrm{IT} \times \mathrm{GS}$ & $\begin{array}{c}\text { Irrigation } \\
\text { treatment (IT) }\end{array}$ & $\begin{array}{c}\text { Growth } \\
\text { stage (GS) }\end{array}$ & $\mathrm{IT} \times \mathrm{GS}$ \\
\hline 0.0000 & 0.0000 & 0.0000 & 0.0000 & 0.0000 & 0.0000 \\
\hline 0.4336 & 0.0020 & 0.0000 & 0.0332 & 0.0168 & 0.0114 \\
\hline 0.0000 & 0.0000 & 0.0000 & 0.0000 & 0.0000 & 0.0000 \\
\hline 0.0000 & 0.0000 & 0.0000 & 0.0000 & 0.0000 & 0.0000 \\
\hline 0.0000 & 0.0000 & 0.0000 & 0.0000 & 0.0000 & 0.0000 \\
\hline 0.0000 & 0.0000 & 0.0150 & 0.0000 & 0.0000 & 0.0000 \\
\hline 0.0000 & 0.0000 & 0.00001 & 0.0000 & 0.0000 & 0.0000 \\
\hline 0.0000 & 0.0000 & 0.0000 & 0.0000 & 0.0000 & 0.0000 \\
\hline 0.0000 & 0.0000 & 0.0000 & 0.0000 & 0.0003 & 0.0000 \\
\hline 0.0001 & 0.2888 & 0.0000 & 0.0002 & 0.0004 & 0.0000 \\
\hline 0.0000 & 0.0000 & 0.0000 & 0.0000 & 0.0000 & 0.0000 \\
\hline 0.0000 & 0.0003 & 0.0000 & 0.0000 & 0.0000 & 0.0000 \\
\hline 0.0000 & 0.0000 & 0.0000 & 0.0000 & 0.0000 & 0.0000 \\
\hline 0.0068 & 0.0001 & 0.0000 & 0.755 & 0.0000 & 0.0000 \\
\hline 0.0000 & 0.2860 & 0.0006 & 0.0011 & 0.0346 & 0.0020 \\
\hline 0.0000 & 0.0000 & 0.0000 & 0.0000 & 0.0000 & 0.0000 \\
\hline
\end{tabular}


$\Psi_{\mathrm{L}}(\mathrm{p}<0.001)$ (Table 2). The $\Psi_{\mathrm{L}}$ values in control plants were significantly higher than in stressed plants $(\mathrm{p}<0.001)$.

LAI values were higher in 2011 than in 2012 (Figure 4), in both years average maximum LAI across treatments were higher in full irrigated than in others treatments, and LAI decreased with increasing drought stress. Maximum LAI differed significantly among treatments. Full irrigation presented the highest value during the plant growth, with a maximum of 4.5 in 2012 and 6.13 in 2011 at the beginning of the grain filling, and the lowest was the rainfed treatment with a maximum of 3.87 and 2.7 in 2011 and 2012, respectively. In both seasons LAI increased until the beginning of grain filling. Occurrence of maximum leaf area index correlated with development stages.

The PSII function during each growth stage of quinoa under different drought stress levels was evaluated through analysis of the recorded OJIP fluorescence transients according to the JIP-test.

The effects of drought stress on the maximum quantum yield of primary photochemistry $\left(\mathrm{F}_{\mathrm{v}} / \mathrm{F}_{\mathrm{m}}\right)$ and the specific and phenomenological energy fluxes for light absorption, excitation energy trapping and electron transport are
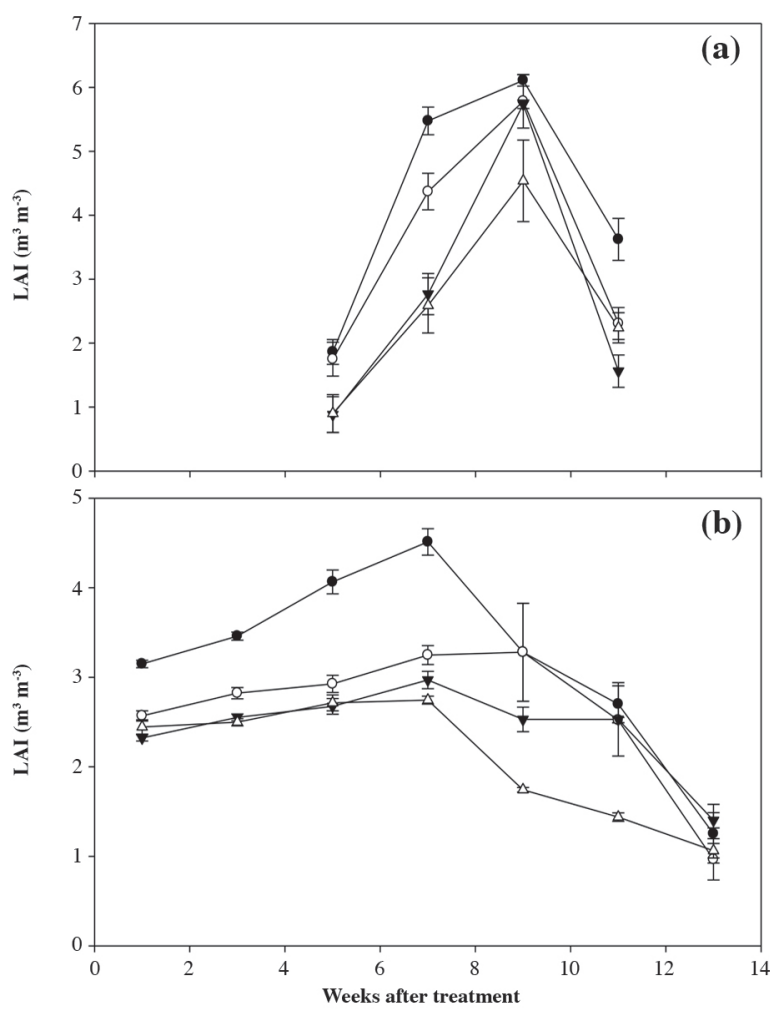

Irrigation treatments: $100 \% \mathrm{ETc}(\bullet), 50 \% \mathrm{ETc}(\circ), 33 \% \mathrm{ETc}(\boldsymbol{\Delta})$, and rain fed $(\Delta)$. Values are means $( \pm$ SE) of four replicates.

Figure 4. Seasonal variation of leaf area index (LAI) during plant cycle in two successive cycles 2011 (a) and 2012 (b) under four level of irrigation treatments: well watered $(100 \% \mathrm{ETc}), 50 \% \mathrm{ETc}, 33 \% \mathrm{ETc}$, and rain fed. presented in the form of a radar plot (Figures 5 and 6). In this plot all the parameters values calculated from the measurements conducted in control plants were normalized to the numeric value of 1 (grey reference line) in order to show the fractional changes in the parameter values of the measurements conducted in plants at each growth stages. All stress treatments induced same trend in the modifications of the JIP-test parameters, although the amplitude of the effects was different (Figures 5 and 6). Drought stress in both years and in all growth stages resulted in the down-regulation of PSII function, where phenomenological flux in both seasons were highly influenced by the irrigation treatments, growth stage and the interaction between treatment and growth stage (Table 2), as indicated by the deactivation of reaction centers (RC/CS), and decreased excitation of trapping energy $\left(\mathrm{TR}_{0} / \mathrm{CS}\right)$ and electron transport $\left(\mathrm{ET}_{0} / \mathrm{CS}\right)$. The specific flux was highly significantly affected by irrigation treatment and growth stage, except electron transfer $\left(\mathrm{ET}_{0} /\right.$ RC) which was not altered by the growth stage in 2011 (Table 2). The $\mathrm{TR}_{0} / \mathrm{RC}$ was not affected by irrigation treatment in 2012. The electron transport rate in an active reaction centre $\left(\mathrm{ET}_{0} / \mathrm{RC}\right)$ was reduced as drought stress increased. In accordance to the observed increase in the effective antenna size of active RCs (ABS/RC), the effective dissipation per active reaction centers $\left(\mathrm{DI}_{0} / \mathrm{RC}\right)$ was increased by increasing drought stress during all the plant cycle in comparison to the control.

In the present study, in leaf, although $\mathrm{F}_{\mathrm{v}} / \mathrm{F}_{\mathrm{m}}$ was lower under stress (Figures 5 and 6), stress-induced changes in $\mathrm{F}_{\mathrm{v}} / \mathrm{F}_{\mathrm{m}}$ were smaller than some JIP parameters.

The three parameters plotted in Figure 7 (data of both seasons in all stages) reflect the quantum yields of the electron transport in PSII, PSI, and between them $\left(\phi_{\mathrm{P} 0}, \phi_{\mathrm{R} 0}\right.$, and $\phi_{\mathrm{E} 0}$, correspondingly). They were highly sensitive to drought stress and strongly decreased at low soil water content. These parameters were used to evaluate the drought stress sensitivity of different sections of the photosynthetic electron-transfer chain. The result revealed a different behavior of these parameters in the different irrigation treatments. Specifically, fully irrigated $(100 \% \mathrm{ETc})$ and rainfed plants showed significant variations in the studied parameters, and are grouped either in the top corner or in the down corner of the plot. In contrast, moderately stressed plant (33\% and 50\%ETc) showed low variation in electron-transport quantum yields. Also, the changes of quantum yields of electron transport from the reaction centre of PSII P680 to $\mathrm{Q}_{\mathrm{A}}$, and from $\mathrm{Q}_{\mathrm{A}^{-}}$to $\mathrm{PQ}\left(\phi_{\mathrm{E} 0}\right)$ were similar, while the quantum yield of the electron transport from the reduced PQ to the PSI acceptors $\left(\phi_{\mathrm{R} 0}\right)$ had a different behavior. Overall a rather narrow trace in 3D space was formed by all of the examined parameters.

Another fluorescence parameter which changed significantly during drought stress (Figures 5 and 6) was the performance index (PI). In general, PI describes the 


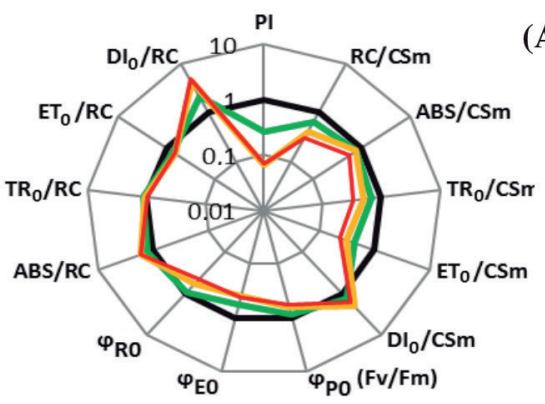

(A)

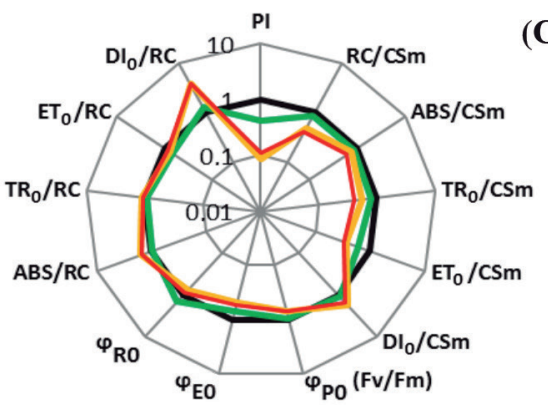

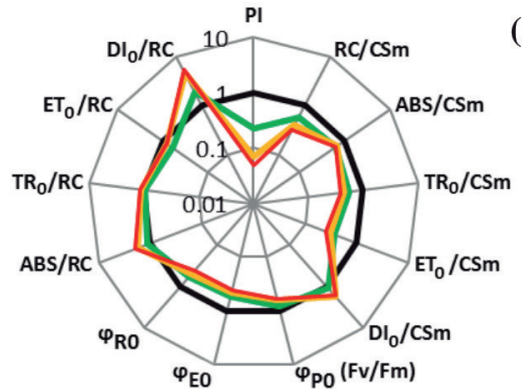

(B)

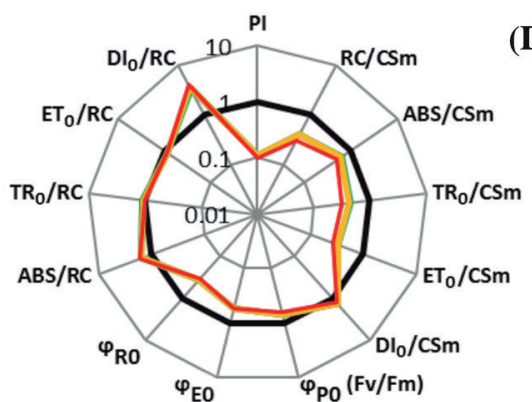

(D)

(E)

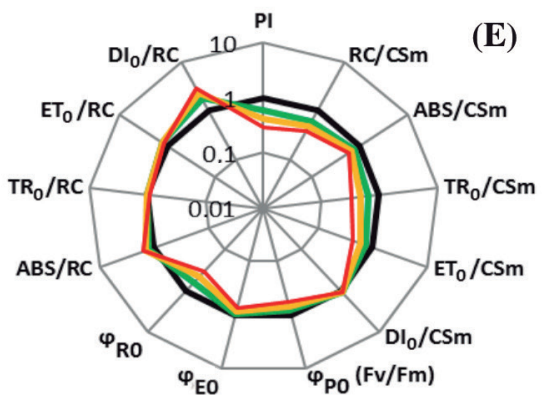

Figure 5. Radar plots depicts different changes in JIP test parameters in 2011 at emergence (A), vegetative (B), flowering (C), grain filling (D), and senescence (E) stages, under four irrigation treatments. The status of the stressed plants $(50 \%$ ETc green line; $33 \%$ ETc yellow line, and rainfed red line) is shown relative to the status of the control $100 \%$ ETc black line. The absorption (ABS), electron transport (ET $)$, trapping $\left(\mathrm{TR}_{0}\right)$, and dissipation $\left(\mathrm{DI}_{0} /\right)$ per RC present the specific energy fluxes and per excited cross section (CSm) present phenomenological energy fluxes, performance index (PI), quantum yield of electron transport from Q-A to the Photosystem I (PSI) end electron acceptor ( $\left.\phi_{\mathrm{R} 0}\right)$, maximum quantum yield of primary photochemistry $\left(\phi_{\mathrm{P} 0}\right)$, quantum yield of electron transport from QA to plastoquinone $\left(\phi_{\mathrm{E} 0}\right)$.

energy conservation between photons absorbed by PSII and the reduction of intersystem electron acceptors. In the present study, the PIABS after exposure to stress was lower in all growing stages (Figures 5 and 6).

\section{DISCUSSION}

The different water supplies between treatments resulted in a different plant water status. It is noteworthy that plant water status, as evaluated by $\Psi_{\mathrm{L}}$, was significantly different compared to the control. It has been argued that leaf $\Psi_{\mathrm{L}}$ may not be the best indicator of drought stress intensity in below-ground organs, because the roots growing in wetted sectors of soil may also influence leaf $\Psi_{\mathrm{L}}$, whereas the dehydrated superficial roots may produce chemical signals inducing stomata closure, before any change in leaf $\Psi_{\mathrm{L}}$ is detectable (Liu et al., 2003).
Moreover, in the present study deficit irrigation plants had significant different $(\mathrm{p}<0.05) \mathrm{g}_{\mathrm{s}}$ values in 2012, whereas there was no clear difference in $g_{s}$ between irrigation treatments in 2011. However it was consistently lower in deficit irrigation treatments than in the control (Wallace, 2000). In fact, increased root-sourced signal, transported upwards in the transpiration stream, have been considered as a potential cause of the observed stomatal closure (Aganchich et al., 2007; Tahi et al., 2007). In a number of experiments using deficit irrigation, it has been found that roots can sense soil drying and produce chemical signals (i.e. increased ABA concentration, xylem sap $\mathrm{pH}$, or apoplectic $\mathrm{pH}$ ) that were transported to the shoots and accounted for the reduction of $\mathrm{g}_{\mathrm{s}}$ and leaf growth (Jacobsen et al., 2009). Consistent with these findings, the results of this study indicate a significant decrease in $g_{s}$ under DI treatments combined to the growth stage effect 

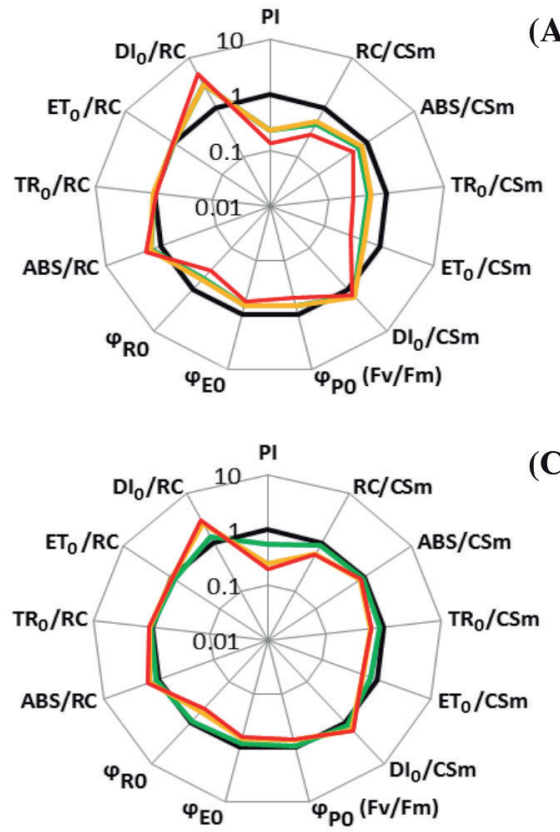

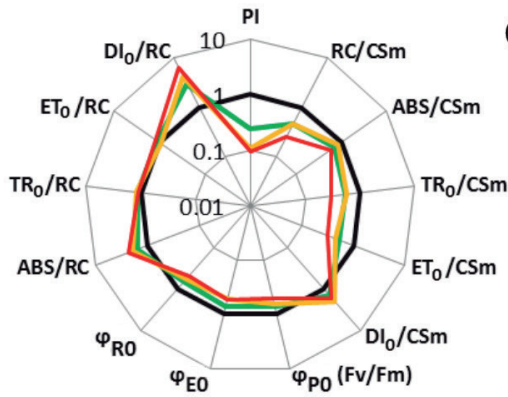

(B)

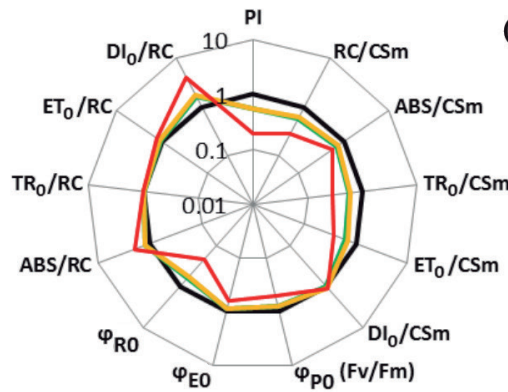

(D)

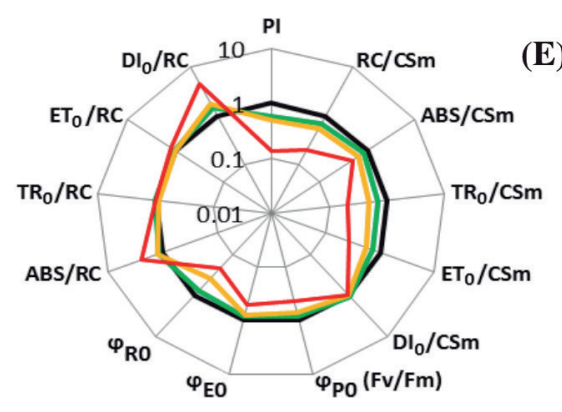

(E)

Figure 6. Radar plots depicts different changes in JIP test parameters in 2012 season at the emergence (A), vegetative (B), flowering (C), grain filling (D) and senescence (E) stages, under four irrigation treatments, the status of the stressed plants (50\% ETc green line; $33 \%$ ETc yellow line, and rain fed red line) is shown relative to the status of the control $100 \%$ ETc black line. Absorption (ABS), electron transport (ET $)_{0}$, trapping $\left(\mathbf{T R}_{0}\right)$, and dissipation $\left(\mathrm{DI}_{0} /\right)$ per $\mathrm{RC}$ present specific energy fluxes and per excited cross section (CSm) present phenomenological energy fluxes, performance index (PI), quantum yield of electron transport from Q-A to the Photosystem I (PSI) end electron acceptor ( $\left.\phi_{\mathrm{R} 0}\right)$, maximum quantum yield of primary photochemistry $\left(\phi_{\mathrm{P} 0}\right)$, quantum yield of electron transport from QA to plastoquinone $\left(\phi_{\mathrm{E} 0}\right)$.

in both season. Furthermore, this drought induced change in LAI where leaf growth and expansion of quinoa plants were significantly and similarly reduced in response to deficit irrigation treatments (Figure 4). Many studies have shown that leaf area development was more sensitive to soil drying (Boyer, 1970).

Several studies have been conducted with respect to the effect on environmental stresses such as salt, heat, and chilling stress on chlorophyll A fluorescence (Ogweno et al., 2009; Zribi et al., 2009). Fluorescence, emitted mainly by PSII antennae chlorophyll A molecules, can serve as an intrinsic probe for monitoring the successive steps of excitation energy transformation (Strasser et al., 2004). The variable part of the fluorescence is directly related to the Qa reduction and it always increases during photoinduced reduction of the quinone acceptor Qa (Duysens and Sweers, 1963). As the level of Qa reduction depends on later stages of energy transformation, the fluorescence signal is sensitive to the overall electron-transfer process. Using the JIP-test approach (Strasser et al., 2000; 2004) the different steps and phases of the fast fluorescence rise (OJIP-transient) can be linked with the efficiencies of electron transfer in PSII, PSI, and between the two photosystems.

The results obtained in the present study showed that stress induced changes demonstrated by the JIP-test were different between all plant growth stages and that PSII was more tolerant to drought stress in the vegetative stage than in the other plant growing stages (Figures 5 and 6). The JIP parameter implicated several sensitive sites of PSII in response to drought stress. For example, in phenomenological fluxes per $\mathrm{CSm}, \mathrm{ABS} / \mathrm{CSm}, \mathrm{TR}_{0} / \mathrm{CSm}$, and $\mathrm{ET}_{0} / \mathrm{CSm}$ were lower under drought stress than in the control (Figures 5 and 6). The decrease in ABS/CSm 


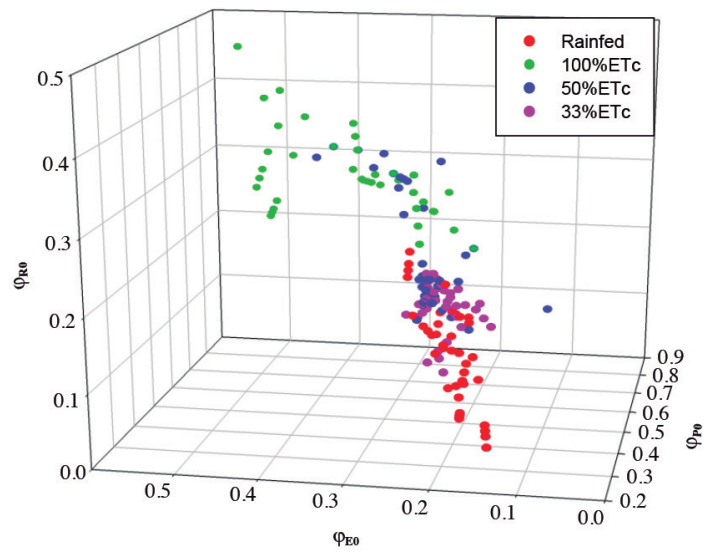

Figure 7. 3D phase diagram showing the relationship between the quantum yields of photo-induced electron transfer from P680 to $Q_{A}$ (maximum quantum yield of primary photochemistry, $\left.\phi_{\mathrm{P} 0}\right)$, from $\mathrm{Q}_{\mathrm{A}}$ to plastoquinone (quantum yield of electron transport, $\phi_{\mathrm{E} 0}$ ), and from PQ to the Photosystem I (PSI) electron acceptors (quantum yield of electron transport, $\left.\phi_{\mathrm{R} 0}\right)$. All individual measurements are shown with different color corresponding to the different irrigation treatments.

reflects an increased density of inactive reaction centers in response to drought stress. Thus, reduced $\mathrm{TR}_{0} / \mathrm{CSm}$ and $\mathrm{ET}_{0} / \mathrm{CSm}$ indicates that active $\mathrm{RCs}$ are converted into inactive RCs, reducing the efficiency of trapping and a decline in PSII activity. Similar results have been reported in heath plants under drought stress (Albert et al., 2011), in spinach leaves under low pH (Tongra et al., 2011) and in tomato leaf under heat stress (Zushi et al., 2012). In contrast, in the specific fluxes $\mathrm{RC}, \mathrm{ABS} / \mathrm{RC}, \mathrm{TR}_{0} / \mathrm{RC}$, and $\mathrm{DI}_{0} / \mathrm{RC}$ were relatively higher under drought stress (Figures 5 and 6). These results indicate that average absorption $(\mathrm{ABS} / \mathrm{RC})$ and trapping $\left(\mathrm{TR}_{0} / \mathrm{RC}\right)$ per active $\mathrm{RC}$ increases owing to the inactivation of some RCs, and that the ratio of total dissipation to the amount of active $\mathrm{RCs}\left(\mathrm{DI}_{0} / \mathrm{RC}\right)$ increases because of high dissipation of the inactive RCs.

The analysis of parameters of the JIP test allowed the localization of the drought induced modifications in the electron transport chain (Strasser et al., 2010). The results of the present study indicate that drought stress induced changes in energy flux were different between PSI and PSII. For example, the energy fluxes $\phi_{\mathrm{R} 0}, \phi_{\mathrm{E} 0}$, and $\phi_{\mathrm{P} 0}$, of PSII were lower under drought stress than in the control (Figures 5 and 6). In addition, we found that the redox reactions were strongly affected. The quantum yields of the reactions close to the PSII reaction center were more tolerant to water deficit (Figure 7). The three JIP-parameters which reflect the quantum yields of photoinduced electron transfer from P680 to Qa $\left(\phi_{\mathrm{P} 0}\right)$. From $\mathrm{Qa}$ to $\mathrm{PQ}\left(\phi_{\mathrm{E} 0}\right)$, and from $\mathrm{PQ}$ to the PSI electron acceptors $\left(\phi_{\mathrm{R} 0}\right)$, can be arranged according to their decreased sensitivity to water deficit in the sequence $\phi_{\mathrm{R} 0}>\phi_{\mathrm{E} 0}>\phi_{\mathrm{P} 0}$ similar behavior of this parameters was demonstrated in bean (Goltsev et al., 2012).
This investigation showed that PI is a very sensitive indicator of the physiological status of quinoa under field conditions of varying water availability. The large changes that occurred in the PI may be interpreted as evidence for considerable modulation of PSII function by irrigation levels. The results presented imply downregulation of photochemical activity with increasing stress, predominantly through PSII RC deactivation. The PI was much more sensitive than the $F_{v} / F_{m}$ ratio, most probably because PI responds to changes in the fast fluorescence rise kinetics between the two fluorescence extremes $\left(F_{0}\right.$ and $\left.F_{m}\right)$, while $F_{v} / F_{m}$ only considers changes in the values of $F_{0}$ and $F_{m}$. The insensitivity of $F_{v} / F_{m}$ to drought stress is a well-known phenomenon in many plant species (Bukhov and Carpentier, 2004).

\section{CONCLUSIONS}

In the present study, JIP-test parameters changed rapidly under drought stress. Furthermore, the photosystem II (PSII) electron transport chain was more influenced by drought stress. These results indicate that, in quinoa leaves, JIP-test can be used as a sensitive method for measuring drought stress, and is a good tool for investigating differences in physiological behavior and action sites such as photosystems I (PSI) and PSII. In addition, for the evaluation of drought stress in quinoa, we propose that the reduction of JIP parameters of PSII can be used to assess drought stress, because those parameters reveal differences between stress and normal conditions. The hypothesis that PSII is more tolerant to drought in the vegetative stage than other stages may play an important role in the quinoa plant's strategy for persistence under drought stress, and optimization of the irrigation schedule. Further studies are required to elucidate the physiological mechanism of the difference in effect on OJIP transients between growth stages.

\section{ACKNOWLEDGEMENTS}

This research was funded by the EU $7^{\text {th }}$ Framework Program through the project "Sustainable water use securing food production in dry areas of the Mediterranean region (SWUP-MED)". The author is grateful to Professor L. Mandi, and Professor N. Ouazzani.

\section{LITERATURE CITED}

Aganchich, B., H. Tahi, S. Wahbi, C.E. Modaffar, and R. Serraj. 2007. Growth, water relations and antioxidant defence mechanisms of olive (Olea europaea L.) subjected to Partial Root Drying (PRD) and Regulated Deficit Irrigation (RDI). Plant Biosystems 141:252-264.

Albert, K.R., T.N. Mikkelsen, A. Michelsen, H. Ro-Poulsen, and L. van der Linden. 2011. Interactive effects of drought, elevated $\mathrm{CO}_{2}$ and warming on photosynthetic capacity and photosystem performance in temperate heath plants. Journal of Plant Physiology 168:1550-1561. 
Allen, R.G., L.S. Pereira, D. Raes, and M. Smith. 1998: Crop evapotranspiration (guidelines for computing crop water requirements). FAO Irrigation and Drainage Paper nr 56. 300 p. FAO, Rome, Italy.

Andreas, R.S., and F. Karen. 2002. Crop water requirements and irrigation scheduling. FAO Sub-Regional Office for East and Southern Africa, Harare, Zimbabwe.

Bertero, H., R. King, and A. Hall. 1999. Photoperiod-sensitive development phases in quinoa (Chenopodium quinoa Willd.) Field Crops Research 60:231-243.

Boyer, J.S. 1970. Leaf enlargement and metabolic rates in corn, soybean, and sunflower at various leaf water potentials. Plant Physiology 46:233-235.

Bukhov, N.G., and R. Carpentier. 2004. Effects of water stress on the photosynthetic efficiency of plants. p. 623-635. In Papageorgiou, G.C., and Govindjee (eds.) Chlorophyll a fluorescence: A signature of photosynthesis. Springer, Dordrecht, The Netherlands.

Cascio, C., M. Schaub, K. Novak, R. Desotgiu, F. Bussotti, and R.J. Strasser. 2010. Foliar responses to ozone of Fagus sylvatica L. seedlings grown in shaded and in full sunlight conditions Environmental and Experimental Botany 68:188-197.

Chaves, M.M., J.P. Maroco, and J.S. Pereira. 2003. Understanding plant responses to drought - from genes to the whole plant. Functional Plant Biology 30:239-264.

Christen, D., S. Schonmann, M. Jermini, R.J. Strasser, and G. Defago. 2007. Characterization and early detection of grapevine (Vitis vinifera) stress responses to esca disease by in situ chlorophyll fluorescence and comparison with drought stress. Environmental and Experimental Botany 60:504-514.

Dos Santos, M.G., R.V. Ribeiro, R.F. de Oliveira, E.C. Machado, and C. Pimentel. 2006. The role of inorganic phosphate on photosynthesis recovery of common bean after a mild water deficit. Plant Science 170:659-664.

Duysens, L., and H. Sweers. 1963. Mechanism of two photochemical reactions in algae as studied by means of fluorescence. Microalgae and Photosynthetic Bacteria 353-372.

Fghire, R., I. Oudou, F. Anaya, O. Benlhabib, S.-E. Jacobsen, and S. Wahbi. 2013. Protective Antioxidant enzyme activities are affected by drought in quinoa (Chenopodium quinoa Willd.) Journal of Biology, Agriculture and Healthcare 3:62-68.

Gao, Q.T., and N.F.Y. Tam. 2011. Growth, photosynthesis and antioxidant responses of two microalgal species, Chlorella vulgaris and Selenastrum capricornutum, to nonylphenol stress. Chemosphere 82:346-354.

Goltsev, V., I. Zaharieva, P. Chernev, M. Kouzmanova, H.M Kalaji, I. Yordanov, et al. 2012: Drought-induced modifications of photosynthetic electron transport in intact leaves: Analysis and use of neural networks as a tool for a rapid non-invasive estimation. Biochimica et Biophysica Acta (BBA) - Bioenergetics 1817:1490-1498

Han, S., N. Tang, H.-X. Jiang, L.-T. Yang, Y.Li, and L.-S. Chen. 2009. $\mathrm{CO}_{2}$ assimilation, photosystem II photochemistry, carbohydrate metabolism and antioxidant system of citrus leaves in response to boron stress. Plant Science 176:143-153.

Jacobsen, S.-E., F. Liu, and C.R. Jensen. 2009. Does root-sourced ABA play a role for regulation of stomata under drought in quinoa (Chenopodium quinoa Willd.) Scientia Horticulturae 122:281-287.

Kalaji, H.M., K. Bosa, J. Kościelniak, and Z. Hossain. 2011a. Chlorophyll a fluorescence-a useful tool for the early detection of temperature stress in spring barley (Hordeum vulgare L.) OMICS: A Journal of Integrative Biology 15:925-934.

Kalaji, H.M., K. Bosa, J. Kościelniak, and K. Żuk-Gołaszewska. 2011b. Effects of salt stress on photosystem II efficiency and $\mathrm{CO}_{2}$ assimilation of two Syrian barley landraces. Environmental and Experimental Botany 73:64-72.

Lin, Z.H., L.S. Chen, R.B. Chen, F.Z.Zhang, H.X. Jiang, and N. Tang. 2009. $\mathrm{CO}_{2}$ assimilation, ribulose-1,5-bisphosphate carboxylase/ oxygenase, carbohydrates and photosynthetic electron transport probed by the JIP-test, of tea leaves in response to phosphorus supply. BMC Plant Biology 9:43.
Liu, F., C.R. Jensen, and M.N. Andersen. 2003. Hydraulic and chemical signals in the control of leaf expansion and stomatal conductance in soybean exposed to drought stress. Functional Plant Biology 30:65-73

Liu, J., and D.C. Shi. 2010. Photosynthesis, chlorophyll fluorescence, inorganic ion and organic acid accumulations of sunflower in responses to salt and salt-alkaline mixed stress. Photosynthetica 48:127-134

Mehta, P., S.I. Allakhverdiev, and A. Jajoo. 2010. Characterization of photosystem II heterogeneity in response to high salt stress in wheat leaves (Triticum aestivum). Photosynthesis Research 105:249-255.

Ogweno, J.O., X.S. Song, W.H. Hu, K. Shi, Y.H. Zhou, and J.Q. Yu. 2009. Detached leaves of tomato differ in their photosynthetic physiological response to moderate high and low temperature stress. Scientia Horticulturae 123:17-22.

Oukarroum, A., S. El Madidi, G. Schansker, and R.J. Strasser. 2007. Probing the responses of barley cultivars (Hordeum vulgare L.) by chlorophyll a fluorescence OLKJIP under drought stress and rewatering. Environmental and Experimental Botany 60:438-446.

Papageorgiou, G.C., and Govindjee (eds.) 2004. Chlorophyll a fluorescence: A signature of photosynthesis. Springer, Dordrecht, The Netherlands.

Redillas, M.C.F.R., R.J. Strasser, J.S. Jeong, Y.S. Kim, and J.K. Kim. 2011. The use of JIP test to evaluate drought-tolerance of transgenic rice overexpressing OsNAC10. Plant Biotechnology Reports 5:169-175.

Sanchez, H.B., R. Lemeur, P.V. Damme, and S.E. Jacobsen. 2003. Ecophysiological analysis of drought and salinity stress of quinoa (Chenopodium quinoa Willd.) Food Reviews International 19:111-119.

Shabala, L., A. Mackay, Y. Tian, S.E. Jacobsen, D. Zhou, and S Shabala. 2012. Oxidative stress protection and stomatal patterning as components of salinity tolerance mechanism in quinoa (Chenopodium quinoa). Physiologia Plantarum 146:26-38.

Shao, R.X., K.B. Wang, and Z.P. Shangguan. 2010. Cytokinininduced photosynthetic adaptability of Zea mays L. to drought stress associated with nitric oxide signal: Probed by ESR spectroscopy and fast OJIP fluorescence rise. Journal of Plant Physiology 167:472-479.

Souza, R.P., E.C. Machado, J.A.B. Silva, A.M.M.A. Lagoa, and J.A.G. Silveira. 2004. Photosynthetic gas exchange, chlorophyll fluorescence and some associated metabolic changes in cowpea (Vigna unguiculata) during water stress and recovery. Environmental and Experimental Botany 51:45-56.

Strasser, R., A. Srivastava, and M. Tsimilli-Michael. 2000. The fluorescence transient as a tool to characterize and screen photosynthetic samples. p. 445-483. Yunus, M., U. Pathre, and P. Mohanty (eds.) Probing photosynthesis: Mechanisms, regulation and adaptation. CRC Press, London, UK.

Strasser, B.J., and R.J. Strasser. 1995. Measuring fast fluorescence transients to address environmental questions: the JIP-test. p. 977 980. Photosynthesis: from light to biosphere. Proceedings of the Xth International Photosynthesis Congress, Montpellier. 20-25 August. Springer, Dordrecht, The Netherlands.

Strasser, R.J., M. Tsimilli-Michael, S. Qiang, and V. Goltsev. 2010. Simultaneous in vivo recording of prompt and delayed fluorescence and 820-nm reflection changes during drying and after rehydration of the resurrection plant Haberlea rhodopensis. Biochimica et Biophysica Acta (BBA) - Bioenergetics 1797:13131326.

Strasser, R.J., M. Tsimilli-Michael, and A. Srivastava. 2004 Analysis of the chlorophyll $a$ fluorescence transient. Chlorophyll a Fluorescence.p. 321-362. In Papageorgiou, G.C., and Govindjee (eds.) Chlorophyll a fluorescence: A signature of photosynthesis Springer, Dordrecht, The Netherlands

Tahi, H., S. Wahbi, R. Wakrim, B. Aganchich, R. Serraj, and M. Centritto. 2007. Water relations, photosynthesis, growth and water-use efficiency in tomato plants subjected to partial rootzone drying and regulated deficit irrigation. Plant Biosystems $141: 265-274$ 
Tongra, T., P. Mehta, S. Mathur, D. Agrawal, S. Bharti, D.A. Los, et al. 2011. Computational analysis of fluorescence induction curves in intact spinach leaves treated at different $\mathrm{pH}$. Biosystems 103:158-163.

Tsonev, T., S. Wahbi, P. Sun, G. Sorreutiuo, and M. Centritto. 2014. Gas exchange, water relations photochemical reflectance index in stress and recovery and their relationships with Quercus ilex plants during water stress and recovery. International Journal of Agriculture and Biology 16:335-341.

van Heerden, P.D.R., M. Tsimilli-Michael, G.H.J. Krüger, and R.J. Strasser. 2003. Dark chilling effects on soybean genotypes during vegetative development: parallel studies of $\mathrm{CO}_{2}$ assimilation, chlorophyll a fluorescence kinetics O-J-I-P and nitrogen fixation. Physiologia Plantarum 117:476-491.

Wallace, J.S. 2000. Increasing agricultural water use efficiency to meet future food production. Agriculture, Ecosystems and Environment 82:105-119.

Waseem, M., A. Ali, M. Tahir, M. Nadeem, M. Ayub, A. Tanveer, et al. 2011. Mechanisms of drought tolerance in plant and its management through different methods. Continental Journal of Agriculture Science 5:10-25.
Winkel, T., M. Méthy, and F. Thénot. 2002. Radiation use efficiency, chlorophyll fluorescence, and reflectance indices associated with ontogenic changes in water-limited Chenopodium quinoa leaves. Photosynthetica 40:227-232.

Yusuf, M.A., D. Kumar, R. Rajwanshi, R.J. Strasser, M. TsimilliMichael, Govindjee, et al. 2010. Overexpression of gammatocopherol methyl transferase gene in transgenic Brassica juncea plants alleviates abiotic stress: Physiological and chlorophyll a fluorescence measurements. Biochimica et Biophysica Acta (BBA) - Bioenergetics 1797:1428-1438.

Zribi, L., G. Fatma, R. Fatma, R. Salwa, N. Hassan, and R.M. Nejib. 2009. Application of chlorophyll fluorescence for the diagnosis of salt stress in tomato "Solanum lycopersicum (variety Rio Grande)". Scientia Horticulturae 120:367-372.

Zushi, K., S. Kajiwara, and N. Matsuzoe. 2012. Chlorophyll a fluorescence OJIP transient as a tool to characterize and evaluate response to heat and chilling stress in tomato leaf and fruit. Scientia Horticulturae 148:39-46. 